\title{
GLOBALIZAÇÃO， EUROPEIZAÇÃo E EDUCAÇÃO DE ADULTOS REFLEXÕES SOBRE O PROGRAMA NOVAS OPORTUNIDADES EM PORTUGAL
}

\author{
GLOBALIZATION, EUROPEANIZATION AND ADULT EDUCATION: REFLECTIONS \\ ON THE NEW OPPORTUNITIES PROGRAM IN PORTUGAL \\ GLOBALIZACIÓN, UNIÓN EUROPEA Y EDUCACIÓN DE ADULTOS: REFLEXIONES \\ ACERCA DEL PROGRAMA NOVAS OPORTUNIDADES EN PORTUGAL.
}

\author{
Daniela Andrade Vilaverde e Silva* \\ Doutora em Educação - Universidade do Minho | Portugal \\ E-mail: dsilva@ie.uminho.pt
}

\begin{abstract}
REVISTA PEDAGÓGICA
Revista do Programa de Pós-graduação em Educação da Unochapecó | ISSN 1984-1566 Universidade Comunitária da Região de Chapecó | Chapecó-SC, Brasil Como referenciar este artigo: VILAVERDE E SILVA. D. A. Globalização, europeização e educação de adultos: reflexões sobre o programa novas oportunidades em Portugal. Revista Pedagógica, Chapecó, v.16, n.32, p. 141-168, jan./jul. 2014.
\end{abstract}

RESUMO: Na alvorada do novo milénio esboçou-se em Portugal uma nova arquitetura na promoção do direito à educação destinada aos adultos: os processos de Reconhecimento, Validação e Certificação de Competências (RVCC), desenvolvidos nos Centros Novas Oportunidades (CNO), conferindo aos adultos certificação escolar (B1, B2, B3 e Secundário) e profissional. Neste artigo, pretende-se refletir sobre: o fenómeno da globalização, a construção do espaço europeu de educação da União Europeia e as suas influências no sector da educação de adultos em Portugal; conhecer as representações dos diretores/coordenadores dos CNO relativamente ao impacto que os mesmos sentiam em relação às diretrizes emanadas pela União Europeia. Os dados obtidos na investigação denunciam a influência dos processos de globalização no contexto local, confirmando a existência de um determinado grau de porosidade neste programa educativo, das normas e diretrizes da União Europeia.

PALAVRAS-CHAVE: Globalização. Europeização. Educação de Adultos.
ABSTRACT: At the dawn of the new millennium was drafted in Portugal a new architecture in promoting the right to education for adult: the processes of recognition, validation and certification of competences (RVCC), developed in New Opportunities Centres (CNO) giving the adult school certification (B1, B2, B3 and Secondary) and professional. In this article, we reflect on: the phenomenon of globalization, the construction of the European Education Space of the European Union and its influences in the adult education sector in Portugal; to know the representations of the directors / coordinators of $\mathrm{CNO}$ regarding the impact that they felt about the guidelines issued by the European Union. The facts obtained in the investigation denounce the influence of globalization processes in the local context, confirming the existence of a certain degree of porosity in this educational program, standards and guidelines of the European Union.

KEYWORDS: Globalization. Europeanization. Adult Education. 
* Doutora em Educação, especialidade Organização e Administração Escolar pela Universidade do Minho. Professora Auxiliar do Instituto de Educação, Universidade do Minho Campus de Gualtar. CEP: 4710-057. Braga - Portugal

\section{INTRODUÇÃO}

Em Portugal, com a entrada do novo milénio, esboçou-se uma nova arquitetura na promoção do direito à educação destinada aos adultos: os Processos de Reconhecimento, Validação e Certificação de Competências (RVCC), conferindo aos adultos certificação escolar (Níveis B1, B2, B3 e Secundário) e profissional.

Os Processos de Reconhecimento, Validação e Certificação de Competências (RVCC) surgem na sequência da criação da Agência Nacional de Educação e Formação de Adultos (ANEFA) consagrada pelo DecretoLei ${ }^{\circ}$ 387, de 28 de setembro 1999, e decorrem do Sistema Nacional de Reconhecimento, Validação e Certificação de Competências. Todavia, em 2002 a ANEFA foi extinta pelo Decreto-lei $\mathrm{n}^{0}$ 208, de 17 de outubro de 2002, sendo as atribuições da mesma integradas numa nova Direção Geral do Ministério da Educação: a Direção Geral de Formação Vocacional (DGFV), tutelada, apenas, pelo Ministério da Educação. Em 2005, a aposta na educação e formação de adultos, através do desenvolvimento dos processos de RVCC, passou a constituir um emblema de referência na política educativa da agenda governamental socialista de José Sócrates. Um dos exemplos concreto do investimento estatal neste setor corresponde ao Programa/ Iniciativa Novas Oportunidades (2005-2012), promovido pelo Ministério da Educação e também pelo Ministério do Trabalho e da Solidariedade Social, tendo sido este um símbolo do investimento governamental na qualificação, de tal modo que em 2006 é alargado o referencial mínimo de formação até ao nível secundário para jovens e adultos e também se consagra uma nova entidade organizacional: a Agência Nacional para a Qualificação (ANQ) que substituiu a DGFV. Os processos de RVCC foram desenvolvidos pelos designados Centros Novas Oportunidades (CNO). Em fevereiro de 2012, a ANQ é substituída pela Agência Nacional para a Qualificação e o Ensino Profissional, através do Decreto-Lei ${ }^{0}$ 36, de 15 de fevereiro de 2012, que marca o fim do Programa Novas Oportunidades.

Atualmente, vivemos numa época caraterizada pelo fenómeno da globalização e pelas tensões e pressões que este fenómeno e os seus processos exercem sobre cada Estado-Nação. Os efeitos dos processos da globalização são múltiplos e atravessam vários domínios: económico, político, social, cultural e também o setor da educação. Neste artigo, pretendemos refletir sobre: a) o fenómeno da globalização, a construção do espaço europeu de educação da União Europeia e as suas influências no sector da educação de adultos; b) conhecer as representações dos diretores/coordenadores dos CNO relativamente ao impacto que os mesmos sentiam em relação às diretrizes emanadas pela União Europeia e que repercussões tiveram no âmbito dos processos de RVCC, tendo em conta uma 
investigação realizada num $\mathrm{CNO}$ do distrito de Braga, Portugal.A investigação decorreu nos anos civis 2010 e 2011, e contemplou as seguintes metodologias: a) entrevistas à equipa técnica do CNO (formadores e técnicos de RVCC); b) a aplicação de um inquérito por questionário aos diretores/ coordenadores dos CNO do Norte de Portugal (NUT III) (com uma amostra de 79,7\%, $\mathrm{n}=55$ ).

$\mathrm{O}$ artigo encontra-se dividido em três partes: primeiramente refletimos sobre o fenómeno da globalização articulado com a educação, numa segunda parte salientamos o papel da União Europeia na construção do espaço europeu de educação e, por fim, apresentamos alguns dados de investigação sobre alguns dos impactos das normas da União Europeia nos Centros Novas Oportunidades.

\section{A GLOBALIZAÇÃO E A EDUCAÇÃO: BREVES REFLEXÕES}

As influências exercidas sobre a educação de adultos são cada vez mais diversificadas, sendo subsidiárias sobretudo do fenómeno da globalização. A globalização é, nos dias de hoje, omnipresente e influência, quer conscientemente, quer inconscientemente, as políticas e as práticas económicas, sociais, religiosas de todos os países do mundo. No entender de Boaventura Sousa Santos (2001), a globalização é um

[...] fenómeno multifacetado, com dimensões económicas, sociais, políticas, culturais, religiosas e jurídicas interligadas de modo complexo [...] é o resultado do surgimento de uma economia mundial, da expansão dos laços transnacionais entre unidades económicas que criam novas formas de tomada de decisão coletivas, do desenvolvimento de instituições intergovernamentais e como que supranacionais.

De modo semelhante, Estêvão (2009, p. 38) considera a globalização como a "interconexão ou interdependência mundial cada vez mais extensa, profunda, rápida e ampla em todos os aspetos da vida social contemporânea, com particular incidência ao nível do capital, bens, trabalho, serviço e ideias”.

Boaventura Sousa Santos (2001) identifica quatro formas de globalização. A primeira forma designada de localismo globalizado é definida como o "processo pelo qual determinado fenómeno local é globalizado com sucesso" (Santos, 2001, p. 71), como, por exemplo, a expansão mundial da língua inglesa. A segunda forma, designase, pelo inverso da primeira, de globalismo localizado e consiste no

impacto específico nas condições locais produzido pelas práticas e imperativos transnacionais, as condições locais são desintegradas, desestruturadas e, eventualmente, 
1 Associado ao conceito de cosmopoliticidade democrática, Estêvão (2009, p. 45) apresenta também o conceito de educação cosmopolítica, a qual deve "posicionar-se de modo a potenciar novos direitos, como o da solidariedade (que deve atravessar divisões e hierarquias de linguagem, etnicidade, religião, território, cultura ou cidadania)". reestruturadas sob a forma de inclusão subalterna (Santos, 2001, p. 71).

Os efeitos que estas duas formas de globalização produzem nos diversospaíses variam consoanteoseugraude desenvolvimento. Assim, enquanto o localismo globalizado é a marca dos países centrais, aos países periféricos "cabe tão só a escolha de globalismos localizados" (Santos, 2001, p. 72). Os países semiperiféricos, por sua vez, refletem um certo hibridismo nas duas formas de globalização, revelando uma tensão entre elas.

Outra forma de globalização, contrária à anterior e identificada pelo autor, é denominada de cosmopolitismo e assenta na "organização transnacional da resistência de Estados-nação, religiões, classes ou grupos sociais vitimizados pelas trocas desiguais de que se alimentam os localismos globalizados e os globalismos localizados" (Santos, 2001, p. 72-73). Trata-se, sobretudo, de um movimento de resistência contra as diferentes formas de desigualdade, de luta contra a exclusão e a hegemonia dos países centrais. Tendo em conta o conceito de cosmopolitismo, é importante sublinhar outros sentidos que o conceito pode ter. Estêvão (2009, p. 40) diferencia o cosmopolitismo hegemónico, que segue a linha de globalização hegemónica, centrado na "visão ocidental e elitista do mundo" e o cosmopolitismo bottom-up ou, como o autor propõe, cosmopoliticidade democrática ${ }^{1}$, "construída a partir de baixo [...] que tem a vantagem de valorizar múltiplas cidadanias e poderes de promover a conversação, de mobilizar as interpretações e acções políticas de alcance global e de desocultar a fragilidade do ser humano" (Estêvão, 2009, p. 40). É este segundo tipo de cosmopolitismo que vai ao encontro do conceito proposto por Boaventura Sousa Santos (2001).

A última forma de globalização desenvolvida pelo autor é designada de património comum da humanidade e decorre também de uma resistência às duas primeiras formas de globalização a qual se baseia nas
lutas transnacionais pela proteção e desmer- cadorização de recursos, entidades, artefac- tos, ambientes considerados essenciais para a sobrevivência digna de uma humanidade e cuja sustentabilidade só pode ser garantida à escala planetária. (Santos, 2001, p. 75)

Estas duas últimas formas de globalização se caracterizam pela resistência à globalização hegemónica, num jogo de forças, de poder e de tensão entre a globalização que pressiona de cima para baixo (hegemónico) e a que resiste de baixo para cima (contra-hegemónica).

Essas tensões e pressões esboçam-se em diferentes graus: podem ser lentas, difusas e ambíguas, sendo considerados por Boaventura Sousa Santos (2001) de baixa intensidade ou, pelo contrário, serem mais rápidas e intensas caracterizadas pela alta intensidade. 
Decorrente dos processos de globalização o papel do Estado-Nação começa a ser reconfigurado, assumindo outros contornos mais diluídos, não só pela perda do seu protagonismo mas também pelas tensões e forças que pendem o fruto das pressões hegemónicas transnacionais. A influência dos processos de globalização repercute-se nos diferentes domínios, não só no económico e político como também no domínio social e da educação. Dale (2001) analisa a relação entre globalização e educação a partir da diferenciação de duas abordagens: a primeira designada de cultura educacional mundial comum (CEMC), desenvolvida por J. Meyer e pela sua equipa de investigadores da Universidade de Stanford (Califórnia); e a segunda denominada de agenda globalmente estruturada para a educação, desenvolvida e definida por Dale (2001).

A primeira abordagem assenta no pressuposto que o "desenvolvimento dos sistemas educativos nacionais e as categorias curriculares se explicam através de modelos universais de educação, de estado e de sociedade" (Dale, 2001, p. 135) e por características distintas de cada Estado-Nação. Nesse contexto, o argumento central desta abordagem institucionalista repousa na ideia de que

$$
\begin{aligned}
& \text { [...] as instituições do Estado-Nação, e o pró- } \\
& \text { prio Estado, devem ser vistos como sendo } \\
& \text { essencialmente moldados a um nível supra- } \\
& \text { nacional através de uma ideologia do mundo } \\
& \text { dominante (o Ocidente), e não como criações } \\
& \text { nacionais autónomas e únicas. Sobre esta } \\
& \text { perspectiva, os estados têm a sua atividade e } \\
& \text { as suas políticas moldadas por cultura e nor- } \\
& \text { mas universais. (Dale, 2001, p. 135). }
\end{aligned}
$$

Esta abordagem enfatiza o papel permeável dos Estados ao se submeterem a uma cultura dominante e homogénea supranacional ocidental, que se repercute nas diferentes áreas sociais, incluindo a da educação. Nesse campo, Dale (2001, p. 137) exemplifica o "isomorfismo global das categorias curriculares em todo o mundo" nos diferentes sistemas de educação nacionais, o qual não acontece "independentemente das diferenças nacionais a nível económico, político e cultural” (Dale, 2001, p. 137). A explicação para a expansão dos sistemas educativos nacionais e o seu grau de homogeneidade curricular vigente nas diferentes sociedades a nível mundial reside numa tendência e missão modernizadora, que ao valorizar, por um lado, o individualismo económico, político e cultural, acaba por imitar "modelos de sociedade padronizados" como forma de legitimação/reconhecimento interno e externo. As instituições são consideradas como "instâncias culturais" do ocidente que enfatizam a racionalidade, o progresso, o individualismo e a justiça.

Nessa abordagem, a globalização é o reflexo da cultura ocidental (como cultura única e hegemónica) nas diferentes sociedades mundiais, cujas forças padronizadoras 
supranacionais de ideias, normas e valores pendem sobre os diferentes Estados-Nação. Como exemplos claros desta força, Dale (2001, p. 158-159) apresenta que "organizações como a UNESCO, a OCDE, o Banco Mundial e muitos outras [...], são vistas como desempenhando um papel essencial enquanto veículos da mensagem da CEMC" embora o papel desses veículos não assuma a mesma intensidade. Essa abordagem reforça, dessa forma, as interferências das diferentes organizações internacionais nos Estados-Nação e as consequências das ações destas forças supranacionais.

A segunda abordagem, agenda globalmente estruturada para a Educação, definida por Dale (2001), comunga de algumas dimensões da primeira abordagem, embora reforce sobretudo as suas diferenças. No âmbito dos seus aspetos mais convergentes, o autor considera a exposição dos Estados-Nação às influências das forças supranacionais, salientando o "reconhecimento de que os quadros interpretativos nacionais são moldados quer supranacionalmente, quer nacionalmente" (Dale, 2001, p. 146).

Contudo, apesar de as abordagens partilharem o efeito das forças supranacionais, ambas divergem na compreensão do fenómeno global e da relação entre educação e globalização. Se na abordagem anterior a globalização é o reflexo da cultura ocidental, nesta abordagem a globalização é "um conjunto de dispositivos político-económicos para a organização da economia global, conduzido pela necessidade de manter o sistema capitalista [...]. A adesão aos seus princípios é veiculada através da pressão económica e da percepção do interesse nacional próprio" (Dale, 2001, p. 146).

A globalização é, nesta abordagem, mais complexa que a anterior, construída a partir de "três conjuntos de actividade relacionados entre si, económicos, políticos e culturais", caraterizadas pelo "hiperliberalismo, governação sem governo e mercadorização e consumismo" (Dale, 2001, p. 146-147). Enquanto, que na abordagem anterior os protagonistas eram as instituições internacionais, nesta abordagem os principais atores personificam os seguintes agrupamentos de Estados: Europa, América e Ásia; os quais “competem ferozmente para fazer avançar o conjunto de acordos globais que lhe sejam mais favoráveis" (Dale, 2001, p. 147) no contexto de uma economia global que integra todas as nações do mundo. A ênfase já não se localiza apenas numa unidade/entidade ou num país hegemónico, mas antes num sistema complexo com novas "formas de governação supranacional" que transformam as condições de procura do lucro, apoiando "o regime de acumulação, assegurando o contexto que nos inibe a sua contínua expansão e fornecendo uma base de legitimação para o sistema como um todo" (Dale, 2001, p. 148). 
Em síntese, podemos considerar que na agenda globalmente estruturada para a Educação, as relações económicas, políticas, culturais e as suas características, no contexto da economia global representam a base da expansão e de legitimação do sistema capitalista, sendo o capitalismo uma "força causal conduzida pela procura do lucro" (Dale, 2001, p. 148). Nesse contexto, a educação emerge como uma "variável dependente" no processo de globalização, a qual converge em torno de três questões que Dale (2001, p. 149) coloca:

A quem é ensinado o quê, como, por quem e em que circunstância?

Como, por quem e através de que estruturas, instituições e processos são governados, organizados e geridos?

Quais são as consequências sociais e individuais destas estruturas e processos?"

Dale (2001) pretende, desse modo, desconstruir o binómio globalização-educação a partir da análise dos princípios e processos de financiamento, fornecimento e de regulação bem como pretende analisar "como é que esta forma de governação se relaciona com concepções mais amplas de governação dentro de uma sociedade”. A globalização tem impactos significativos sobre a educação pela via indireta do Estado e pela atuação no seu modo de regulação, os quais se encontram moldados tanto por forças supranacionais como por forças político-económicas nacionais. Cada vez mais, a análise deste binómio tende a ser considerada num quadro de uma economia política global e não tanto como um problema localmente percebido. Nesta segunda abordagem, a tónica é colocada não só nos efeitos das tensões supranacionais, mas também nas pressões económicas, originadas pelas demandas do processo de acumulação capitalista.

Embora numa primeira análise as abordagens apresentadas possam ser entendidas como antagónicas, Dale (2001) defende, contudo, a sua complementaridade pela possibilidade de ambas introduzirem elementos de reflexão acerca do binómio globalização-educação. O impacto, ou a absorção por parte das políticas educativas nacionais dos modelos hegemónicos mundiais ou supranacionais, deve também ser entendido no quadro de um movimento que recontextualize a autonomia dos Estados-Nação no âmbito de uma globalização contrahegemónica.

Todavia, o caminho dos diferentes Estados-Nação parece ser diferente. Afonso (2001), com base em estudos sobre o impacto da globalização nas políticas educativas portuguesas, reconhece que:

[...] na fase actual, a prioridade é direcionada para o processo de acumulação. O Estado actual agora tendo como principal objetivo a competitividade económica. (Afonso, 2001, 42). 
Com base nos estudos sobre o ensino profissional e o ensino superior em Portugal, o autor reconhece que em Portugal a educação está submetida ao fenómeno da globalização de baixa intensidade, onde a luta social e as tensões dão sentido às políticas públicas de projetos emancipatórios. No entanto, e apesar do contágio dos modelos supranacionais nas políticas educativas nacionais também se encontram algumas resistências, sendo que o autor reconhece as mudanças no papel do Estado nomeadamente "de o protagonismo do Estado estar a manter-se, muito embora a sua centralidade, responsabilidade e visibilidade sociais estarem, simultaneamente, a esbater-se. (Afonso, 2001, p. 37).

Nesse contexto de globalização, novos papéis são redimensionados ao Estado, sendo este agora desafiado a interpelar a sociedade civil para a concretização de muitos direitos sociais, introduzindo "novas representações e conceções em torno do bem comum e do espaço público" (Afonso, 2001, p. 37), convocando novos atores sociais, em especial do terceiro setor, introduzindo nuances de um quase mercado. Antunes (2001, p. 165) também corrobora as metamorfoses ocorridas no papel do Estado em função dos novos processos de globalização reconhecendo que a "emergência de uma nova forma de atuação do Estado O Estado de Competição ("Competition State") (Cerny, 1990) - está entre as mudanças de maior relevo para a formação de uma agenda globalmente estruturada para a educação". Esta forma de Estado, ao serviço do processo de acumulação vem redimensionar as prioridades do papel do Estado (nomeadamente as de controlo e de legitimação). Nessa linha de pensamento de Antunes (2001), o processo de legitimação sofre também alterações, nomeadamente ao nível da partilha de responsabilidades, "o Estado, no que toca ao bem estar social, 'com modalidades' privadas, de mercado ou comunitários e solidários, para o fornecimento e distribuição de bens e serviços sociais". Este novo tipo de fornecimento vem, necessariamente, colocar em causa os direitos de cidadania a partir da consequente redução dos serviços públicos sociais para níveis aceitáveis de legitimação.

Os processos de globalização originam novas formas de atuação do Estado, conceptualizados já não pela forma de Estado-Providência, mas antes como competidor, gravitando a sua ação pela ênfase proporcionada aos domínios económico e político, com claras repercussões no domínio social. Nesse âmbito, e tendo em conta os diferentes graus de porosidade de cada Estado-Nação em relação aos processos de globalização e à influência de certas organizações internacionais, cada Estado-Nação vai sofrendo alterações decorrentes dessas tensões. 


\section{A UNIÃO EUROPEIA E A CONSTRUÇÃO DO ESPAÇO EUROPEU DE EDUCAÇÃ̃O}

A partir da adesão à (antiga) Comunidade Económica Europeia (CEE), em janeiro de 1986, Portugal vai se beneficiar do designado Fundo Social Europeu que compreende um conjunto de quadros comunitários de apoio que, juntamente com o Estado Português, vão proporcionar um impulso no campo da educação/formação de adultos. A influência das políticas educativas da União Europeia nas políticas educativas de adultos portuguesas tem constituído objeto de estudo em várias investigações, na qual destacam-se os trabalhos de Teodoro (2001), Antunes (2004, 2008), Lima (2010), Guimarães (2010), Barros (2011), Cavaco (2009) e Ávila (2008).

Um dos contributos importantes sobre a genealogia da europeização das políticas de educação e formação, é fornecido por Antunes (2008). Segundo a autora, a intervenção da política comunitária no campo da educação é dividida em duas etapas e quatro fases: a $1^{\mathrm{a}}$ etapa ocorre entre a década de 1970 e prolonga-se até 1992 com a assinatura do Tratado da União Europeia. A $2^{\mathrm{a}}$ etapa, começa com o Tratado e prolonga-se até aos dias de hoje, conforme apresentamos no seguinte quadro:

Quadro 1 - Etapas da Europeização das políticas de educação e formação

\begin{tabular}{|c|c|c|c|}
\hline \multicolumn{2}{|c|}{$\mathbf{1}^{\text {a }}$ Etapa (1970 - 1992) } & \multicolumn{2}{|c|}{$\mathbf{2}^{\mathbf{a}}$ Etapa (1992-20...) } \\
\hline $\begin{array}{c}\text { Emergência da intervenção } \\
\text { política comunitária }\end{array}$ & \multicolumn{2}{|c|}{$\begin{array}{c}\text { Edificação de uma } \\
\text { política comunitária }\end{array}$} \\
\hline $\mathbf{1 9 7 1 - 1 9 8 6}$ & $\mathbf{1 9 8 6 - 1 9 9 2}$ & $\begin{array}{c}\mathbf{1 9 9 2 -} \\
\mathbf{1 9 9 8} / 1999\end{array}$ & $\begin{array}{c}\mathbf{1 9 9 8} / \mathbf{1 9 9 9 -} \\
\mathbf{2 0} . . .\end{array}$ \\
\hline $\begin{array}{c}\text { Institucionalização } \\
\text { da Educação como } \\
\text { área de ação }\end{array}$ & $\begin{array}{c}\text { Preparação } \\
\text { da ação } \\
\text { comunitária }\end{array}$ & $\begin{array}{c}\text { Ampliação } \\
\text { da esfera de } \\
\text { interesse }\end{array}$ & $\begin{array}{c}\text { Espaço } \\
\text { Europeu de } \\
\text { Educação }\end{array}$ \\
\hline
\end{tabular}

Fonte: Construído a partir Antunes (2008).

No âmbito da $1^{\mathrm{a}}$ etapa, a autora considera a existência de duas fases. Uma primeira fase que decorre de 1971 até 1986, na qual se regista o "primeiro afloramento de iniciativas no campo da educação ao nível comunitário" (Antunes, 2008, p. 17) e onde ocorre a institucionalização da educação como área de cooperação e de ação comunitária.

A segunda fase tem início em meados da década de 1980, com o Ato Único Europeu e prolonga-se até 1992. Nesta segunda fase, dá-se a intensificação da intervenção da política comunitária no setor da educação através dos Programas de Ação Comunitários. É precisamente nesta segunda fase que a autora situa o início do processo de europeização da educação no contexto comunitário, na qual refere que:

[...] é possível identificar dimensões da intervenção política pública em educação em que 
as instituições da Comunidade/União Europeia e os sistemas políticos nacionais podem ser vistos como tendendo a constituir uma totalidade (cf. Andersen \& Elianssen, 1993a, 1993b), não forçosamente integrada ou isenta de conflitos, mas, pelo contrário, consideravelmente fragmentada, difusa e contraditória. (Antunes, 2008, p. 18).

Assim sendo, a partir do Ato Único Europeu, intensificam-se e constroem-se, a partir de um conjunto de entendimentos comuns, orientações para todos os EstadosMembros "tendentes a estabelecer uma matriz discursiva que redefine a educação em torno de um conjunto de vectores ou polos discursivos ideológicos" (Antunes, 2008, p. 18).

Na segunda etapa ocorre a edificação de uma política comunitária na área da educação e do Espaço Europeu de Educação. À semelhança da etapa anterior, esta também é constituída por mais duas fases: a terceira que ocorre entre o ano de 1992 e termina nos anos de 1998/1999 e uma quarta que se inicia em finais da década de noventa e prolonga-se até os nossos dias.

A terceira fase é caracterizada pela ampliação da esfera de intervenção da União Europeia. Esta fase é multifacetada e regista um conjunto de inovações, estratégias que redimensionam o papel da intervenção comunitária no campo da educação não só ao nível das competências, mas também ao nível da constituição de organismos, do desenvolvimento de programas de ação, da publicação de documentação orientadora dos "entendimentos comuns" para a educação e legitimando o seu campo de ação. Decorrente do Tratado de Maastricht, mais tarde do tratado de Amsterdã (1997), são definidas competências específicas da União Europeia em matéria de educação.

Ao nível organizacional, a ênfase recai no Conselho da União Europeia, sendo este constituído pelos Ministros da Educação dos Estados-membros adquirindo o estatuto de um dos órgãos da União.

No campo de ação desta dinamização do setor educativo, são publicados dois livros brancos: a) um sobre o Crescimento, Competitividade e Emprego: os desafios e as pistas para entrar no século XX; e b) Ensinar e Aprender: Rumo à Sociedade Cognitiva (1995).

Essas obras vêm contribuir para uma futura regulamentação dos Estados-Membros no campo da Educação de Adultos, em particular o segundo Livro Branco sobre a Educação e a Formação. O seu objetivo é "contribuir, com as políticas de educação e formação dos EstadosMembros, para colocar a Europa na via da sociedade cognitiva, baseada na aquisição de conhecimentos, onde ensinar e aprender são um processo contínuo ao longo da vida”. A ideia nuclear de sociedade cognitiva assenta na projeção de uma sociedade onde cada indivíduo pode 
construir a sua própria qualificação, reforçando o mérito da sua inteligência. Assim, numa sociedade cada vez mais complexa, o Livro Branco distingue três grandes tendências sociais ou, como os autores designam, "choques motores": a) o choque da sociedade da informação; b) o choque da mundialização; e c) o choque da civilização científica e técnica. Desses três choques regista-se a íntima relação entre as modificações das relações laborais com a educação. Se atendermos à função que a educação aqui parece desempenhar, esta reduz-se a uma mera adaptação da educação aos contextos de trabalho, o que coloca a educação numa relação de subordinação face aos imperativos económicos, assentes numa racionalidade tecnocrata. A ideia de uma educação para a cidadania encontra-se, claramente, ausente na procura da "sociedade cognitiva”. Esta leitura é também subsidiária do duplo desafio enunciado: é económico na medida em que, aberta ao mundo, a União Europeia deve reforçar constantemente a sua competitividade, é social porque responde ao imperativo de luta contra a exclusão”.

Estes desafios reiteram a vertente economicista deste marco, embora alertem também, num segundo plano, embora com menos intensidade, para uma vertente mais social. Todavia, esta inclusão no seio de um contexto de uma ampla competitividade pode ser, em nosso entender, uma inclusão gestionária preocupada em gerir a exclusão em níveis legitimados socialmente, mas altamente potenciadores de gerar novas exclusões em virtudes das pernicidades dos mercados e das competitividades. Esta fase representa uma amplificação do campo educativo no contexto de União Europeia, de uma orientação política e de um "pensamento programático ideológico [...] por orientações vistas como imperativas que decorrem das prioridades ou necessidades percepcionadas com origem na economia" (Antunes, 2008, p. 20). Portanto,

[...] a política de aprendizagem ao longo da vida da CE pode-se dizer que seja primeiramente direcionada ao crescimento económico e aumento da produtividade. Direciona a necessidade de sistemas de emprego flexíveis e os meios de resposta à instabilidade envolvida em novos padrões de emprego. A necessidade de expandir sistemas de formação está relacionada com a luta contra a exclusão social e de criação de condições para a progressão social" (Griffin, 1999, p. 339, tradução nossa).

Nesse âmbito, emergem os conceitos de sociedade de aprendizagem, do conhecimento da informação ou aprendizagem ao longo da vida; definindo uma agenda e um novo mandato para a Educação no contexto comunitário das suas instituições.

A quarta fase, definida como a edificação, articulação sistémica de políticas do Espaço Europeu de Educação 
formal, reforça o processo de europeização das políticas educativas. A criação de um Espaço Europeu de Educação (Dale, 2008) desenvolve-se no âmbito de uma cooperação reforçada e no contexto em que a "União Europeia tende a ampliar e aprofundar a sua capacidade de actuação e influência redesenhando a fronteira da sua acção em termos quer de áreas políticas quer de limites territoriais" (Antunes, 2008).

Nesse contexto, o espaço comunitário abre as suas fronteiras ao contexto europeu no seio dos processos de globalização, procurando "desenvolver um nível de atuação política, nos domínios da educação e da formação, de escala não apenas comunitária mas europeia" (Antunes, 2008, p. 22), designada por espaço europeu. É precisamente nesta "nova entidade, cujos contornos políticos institucionais e culturais são deixados na bruma" (Antunes, 2008, p. 22) que despoletam os programas, propostas, projetos e declarações políticas, cujos exemplos mais ilustrativos são o processo de Bolonha (1999) e o programa de Educação/ Formação (2010).

O Memorando sobre a aprendizagem ao longo da vida e a comunicação da Comissão Tornar o espaço europeu de aprendizagem ao longo da vida uma realidade, vêm reforçar este projeto europeu. Defendendo uma nova era - a era do conhecimento - o Memorando vem colocar a Europa, no seu todo, num contexto de mudança. Assim, é definido que a "Europa está em transição para uma sociedade e uma economia assentes no conhecimento" (CCE, 2000, p. 5). Porém, este conhecimento vem apelar a uma nova sociedade inspirada e orientada por princípios económicos, como esclarece o seguinte excerto:

Mais do que nunca, o acesso a informações e conhecimentos atualizados, bem como a motivação e as competências para usar esses recursos de forma inteligente em prol de si mesmo e da comunidade, estão a tornar-se a chave do reforço da competitividade da Europa e da melhoria da empregabilidade e da adaptabilidade da força de trabalho. (CCE, 2000, p. 5).

Portanto, conhecimento, empregabilidade e adaptabilidade figuram conceitos-chave na nova era do conhecimento e da aprendizagem ao longo da vida. Neste documento são também identificados os dois objetivos da aprendizagem ao longo da vida: "promover a cidadania ativa e fomentar a empregabilidade" (CCE, 2000, p. 6). Ao longo do documento é frequente a associação do conceito de aprendizagem ao longo da vida com os conceitos de competência, empregabilidade, pelo que nos permite afirmar que assistimos à revalorização de um novo contexto educativo virado para a economia e para a empregabilidade, como nas fases anteriores definidas por Antunes (2008). Nesse contexto, a cidadania ativa encontra-se virada para 
a empregabilidade que, por sua vez, apela à participação social. Assim, como se afirma no Memorando:

A empregabilidade - a capacidade de assegurar um emprego e de o manter - é não apenas uma dimensão central da cidadania ativa, mas também uma condição decisiva do pleno emprego e da melhoria da competitividade e prosperidade europeias na "nova economia. (CCE, 2000, p. 6).

O conceito de aprendizagem ao longo da vida passa a ser o motor de uma engrenagem assente numa lógica essencialmente económica, onde também se reforça o conceito de competência, associado ao contexto de trabalho. Esta aprendizagem é considerada em função das suas várias dimensões: formal, não-formal e informal. O desenvolvimento e a execução da aprendizagem ao longo da vida pressupõe uma combinação entre diferentes entidades, promovidas pelo estabelecimento de estratégias de cooperação e de parcerias, entre os governos dos países membros, mas também da intervenção de órgãos locais, regionais e de organizações da sociedade civil. Sublinhase, nesta agenda, o papel de que cada Estado-Membro não passa pela provisão desta aprendizagem ao longo da vida, mas passa antes pelo papel de promotor e avaliador de um programa supranacional indutor de boas práticas num contexto comunitário.

$\mathrm{Na}$ construção da aprendizagem ao longo da vida, a Comissão define seis mensagens-chave de apoio à ação, sendo uma delas - mensagem 4 - dedicada ao objetivo de melhorar significativamente a forma como são entendidos e avaliados a participação e os resultados da aprendizagem, em especial da aprendizagem não-formal e informal. A procura pela certificação das aprendizagens é justificada deste modo:

[...] os diplomas, os certificados e as qualificações são um importante ponto de referência para empregadores e indivíduos no mercado de trabalho e nas empresas. A crescente procura de mão-de-obra qualificada por parte dos empregadores e a concorrência cada vez mais acentuada entre indivíduos para conseguir e manter um emprego estão a induzir uma procura muito mais acentuada de formação reconhecida. Como modernizar mais eficazmente os sistemas e as práticas de certificação nacionais face às novas condições económicas e sociais tornou-se uma questão política e profissional importante no conjunto da União. (CCE, 2000, p. 17).

As qualificações e certificações impõem-se, neste sentido, em articulação estreita com o mercado de trabalho, servindo, sobretudo, interesses económicos e não interesses ligados ao desenvolvimento pessoal e social de cada indivíduo. 
O reforço pelo reconhecimento da aprendizagem ao longo da vida mais uma vez se articula com uma lógica económica e com as noções de empregabilidade e competitividade. Nesse contexto, o Memorando propõe como medidas de ação o desenvolvimento de sistemas da qualidade para a 'validação da anterior aprendizagem empírica” (CCE, 2000, p. 18). Este sistema da qualidade assenta num processo de avaliação e reconhecimento no indivíduo dos "conhecimentos, das competências e da experiência adquirida durante longos períodos e em diversos contextos, incluindo situações de aprendizagem não-formal e informal" (CCE, 2000, p. 18).

A comunicação da Comissão Tornar o espaço europeu de aprendizagem ao longo da vida uma realidade vem ampliar a noção de aprendizagem ao longo da vida. Logo no início são introduzidos novos papéis à aprendizagem para além da sua relação com a empregabilidade presente no Memorando. Assim, os objetivos da aprendizagem passam a incluir "a cidadania ativa, o desenvolvimento individual e a inclusão social, bem como aspetos relacionados com o emprego" (CCE, 2001, p. 4). A aprendizagem ao longo da vida adquire uma nova definição e passa a ser definida como: "toda a actividade de aprendizagem em qualquer momento da vida, com o objectivo de melhorar os conhecimentos, as aptidões e competências, no quadro de uma perspectiva pessoal, cívica, social e/ou relacionada com o emprego" (CCE, 2001, p. 10). Os conceitos-chave dessa nova tendência de aprendizagem ao longo da vida e da sociedade do conhecimento são reforçados em torno de: empregabilidade, competências, valorização das aprendizagens e reconhecimento de competências.

Esses conceitos são fundamentais para a construção do Espaço Europeu de Educação e para o reforço do papel da Europa no contexto mundial, como refere o Comunicado: "em termos económicos, a empregabilidade e adaptabilidade dos cidadãos são vitais para que a Europa possa prosseguir o seu escopo de se tornar a sociedade do conhecimento mais competitiva e dinâmica do mundo" (CCE, 2001, p. 7).

Dale (2008) analisa a relação entre a construção de um Espaço Europeu de Educação e a construção da "Europa" como entidade, a qual tem sido crucial para o desenvolvimento de uma política de educação europeia com claras repercussões nas políticas educativas dos Estados Membros. Nesta análise, o autor focaliza tanto o contexto externo como interno desta construção. No âmbito do contexto externo, sinaliza, sobretudo, quatro mudanças que influenciam a construção do Espaço Europeu de Educação: a) as "mudanças no contexto político-económico mais abrangente" decorrentes da intensificação do liberalismo e da deslocação das relações entre o Estado e a economia; b) mudanças na "arquitetura" 
dos sistemas educativos e as relações com o capitalismo e a modernidade; c) as mudanças de concepção quanto ao mandato e capacidade dos sistemas educativos, assentes na proliferação da procura de ferramentas fiáveis de avaliação da educação e da sua eficácia; d) mudanças no valor atribuído ao contributo dos sistemas educativos, os quais têm sido considerados na concepção quanto ao mandato e capacidade dos sistemas educativos, que têm sido considerados "deficitários, em termos dos contributos que podem dar às agendas da competitividade e da Economia do conhecimento/aprendizagem ao longo da vida" (Dale, 2008, p. 19). Nesse sentido, os sistemas educativos necessitam de uma "transformação, tanto quanto aos fins como quanto aos meios" (Dale, 2008, p. 19).

As respostas a estas quatro mudanças condicionam a construção de um Espaço Europeu de Educação. Um marco fundamental propiciador também de mudanças na natureza e envolvimento da União Europeia na política educativa foi a Declaração de Lisboa 2000.

Esta declaração veio delinear um conjunto de marcos para a análise da construção do Espaço Europeu de Educação. Assim, Dale (2008) identifica três estádios de desenvolvimento desse espaço europeu, conforme reproduzimos no seguinte quadro:

\begin{tabular}{|c|c|c|c|c|}
\hline & Governança & Mecanismos & Propósitos & Europa \\
\hline $\begin{array}{l}\text { Fase } 1 \\
\text { Pré- } \\
\text { Lisboa }\end{array}$ & $\begin{array}{l}\text { Grupos de } \\
\text { trabalho em } \\
\text { EM (Estados } \\
\text { Membros) }\end{array}$ & Indicadores & $\begin{array}{l}\text { Concepção } \\
\text { comum de } \\
\text { Educação }\end{array}$ & $\begin{array}{c}\text { Coordenadora } \\
\text { de experiências } \\
\text { nacionais/ } \\
\text { definidora de } \\
\text { Qualidade } \\
\end{array}$ \\
\hline $\begin{array}{c}\text { Fase } 2 \\
\text { Lisboa } \\
2000- \\
2005\end{array}$ & $\begin{array}{c}\text { MAC } \\
\text { (Método de } \\
\text { Coordenação } \\
\text { Aberta) }\end{array}$ & $\begin{array}{l}\text { Benchmarks, } \\
\text { Boas práticas }\end{array}$ & $\begin{array}{c}\text { Intensificação } \\
\text { de problemas } \\
\text { e coordenação } \\
\text { de política } \\
\text { comuns, } \\
\text { meios } \\
\text { diferentes }\end{array}$ & $\begin{array}{l}\text { Orquestradora } \\
\text { de um divisão } \\
\text { funcional e } \\
\text { de escala a } \\
\text { governação } \\
\text { educacional }\end{array}$ \\
\hline $\begin{array}{c}\text { Fase } 3 \\
\text { Pós- } \\
\text { Lisboa } \\
\text { Revisão } \\
\text { de } \\
\text { médio } \\
\text { prazo }\end{array}$ & $\begin{array}{c}\text { Quadro de } \\
\text { Referência } \\
\text { Único } \\
\text { (Aprendizagem } \\
\text { ao Longo da } \\
\text { Vida - ALV) }\end{array}$ & $\begin{array}{c}\text { Metas } \\
\text { (Ex. } \\
\text { Investimento) }\end{array}$ & $\begin{array}{l}\text { Objetivos } \\
\text { comuns, via } \\
\text { comum }\end{array}$ & $\begin{array}{c}\text { Criadora de } \\
\text { novos setores } \\
\text { europeus } \\
\text { de "Política } \\
\text { Social" e de } \\
\text { "política do } \\
\text { conhecimento" }\end{array}$ \\
\hline
\end{tabular}

Na primeira fase, anterior à Declaração, denominada pelo autor de Pré-Lisboa: definir qualidade como base de comparação e decorrente da ausência de consenso sobre o conteúdo de educação, criam-se condições para a emergência de "ferramentas de avaliação", possibilitando o surgimento de bases para o Espaço Europeu de Educação e para a construção de uma política educativa europeia. O interesse da União Europeia recai na definição de 
2 No documento intitulado: Conclusões do Conselho sobre os níveis de referência dos resultados médios na educação e na formação (Benchmarks). um conjunto de indicadores de qualidade no final dos anos 1990. A importância desses indicadores reside no facto de "os indicadores serviram expressamente para 'permitir aos países aprenderem uns com os outros através da comparação de interesses comuns e diferenças partilhadas', bem como, de os benchmarks servirem para dotar os políticos com pontos de referências" (Dale, 2008, p. 23). Todavia, esta valoração acabaria por se afastar de uma "avaliação de eficiência, no sentido da cooperação em função de objetivos comuns”.

A segunda fase, coincidente com o Conselho de Lisboa, visa a construção do Espaço Europeu de Educação, através de uma nova metodologia: o Método Aberto de Coordenação (MAC). Procurando conciliar a diversidade nacional dos Estados Membros, este método pressupunha a existência de uma "convergência regional com diversidade nacional" (Dale, 2008, p. 23). Esta nova metodologia implicava a fixação de orientações para a União, o estabelecimento de "indicadores e benchmarks quantitativos e qualitativos ao nível dos melhores do mundo e à medida das necessidades dos diferentes Estados-Membros e setores, como meio de comparar as melhores práticas”, a transposição destas "orientações para as políticas nacionais e regionais, definindo metas específicas" e a sua monitorização periódica, avaliação e revisão por pares (Dale, 2008).

A definição de "benchmarks de desempenho (ou 'boas práticas') podem ser usadas internacionalmente para estabelecer limites proscritos/exclusivos para a ação dos Estados Membros e os benchmarks, enquanto ferramentas políticas, podem ser usadas para alinhar supranacionalmente as suas políticas" (Dale, 2008, p. 26). $\mathrm{O}$ estabelecimento desses indicadores e dos benchmarks passa a funcionar como mecanismos de regulação tanto nacionais como supranacionais. A título de exemplo, e no âmbito da aprendizagem ao longo da vida, o Conselho da União Europeia ${ }^{2}$ definiu, em 7 de maio de 2003, que

Na sociedade do conhecimento, todos os indivíduos têm de atualizar e complementar os seus conhecimentos, aptidões e competências ao longo da vida para poderem maximizar o seu desenvolvimento pessoal e manter e melhorar a sua situação no mercado de trabalho. Por conseguinte, até 2010, o nível médio de participação na aprendizagem ao longo da vida na União Europeia deverá corresponder pelo menos a $12,5 \%$ da população adulta em idade ativa (grupo etário dos 25 aos 64 anos). (Conselho da União Europeia, 2003, p. 6).

Todavia, a introdução de benchmarks e a regulação supranacional derivada do MAC, poderá, como nos alerta Lima (2010a, p. 46), revelar-se como

[...] um método que se define como aberto mas que, na prática, evidencia poderosos instrumentos de convergência e de isomorfismo, 
3 A este propósito de governação do programa, vale a pena fazer referência à criação do grupo "Coordenação da Educação e Formação 2010", composto por representantes ministeriais e parceiros sociais. baseados em múltiplos instrumentos, entre os quais a emulação e a competição, induzidas pela definição de benchmarks, por variados processos de monitorização, pilotagem e avaliação.

A terceira e última fase designada pelo autor de Aprendizagem ao longo da vida como um Programa Integrado Único vem colmatar algumas falhas da fase anterior, na medida em que volvidos cinco anos de vigência da segunda fase, os resultados alcançados e a revisão da agenda de Lisboa revelaram-se "pouco lisonjeiras" (Dale, 2008, p. 26).

Os resultados obtidos nos relatórios da Comissão Europeia, tanto no de 2004 como no de 2006, revelaram percentagens insuficientes de participação dos adultos no quadro da aprendizagem ao longo da vida, tendo, contudo, este último enfatizado a necessidade de acelerar a velocidade da implementação do programa de Educação e Formação 2010, a definição de metas e a melhoria da governação do programa ${ }^{3}$. Face a estes resultados, tornava-se necessário uma "definição mais apertada das metas a atingir, em relação aos objetivos de desenvolvimento económico e a métodos alternativos de difusão e implementação de programas da UE” (Dale, 2008, p. 26).

Neste cenário de reorientação dos objetivos já traçados, a aposta da União Europeia recai num "programa de ação integrado no domínio da aprendizagem ao longo da vida" que passaria a constituir a base de uma nova geração de programas de Educação da União Europeia para o período de 2007-2013.

Em 2006 é então preparado um novo quadro comunitário designado de Quadro de Referência Estratégico Nacional (QREN). Integrado neste âmbito emerge o programa global de aprendizagem ao longo da vida para 2007-2013, definido pela Comissão das Comunidades Europeias em 23 de outubro de 2006. Este programa intitula-se Educação de adultos: nunca é tarde para aprender. No comunicado, o investimento na Educação de Adultos é justificado como uma necessidade de promover a participação dos adultos no quadro de uma aprendizagem ao longo da vida. Nessa linha,

O papel da educação de adultos neste contexto, para além da sua contribuição para o desenvolvimento e a realização pessoais, está a ser cada vez mais reconhecido pelos programas nacionais de reforma dos Estados-Membros. Contudo, com algumas exceções, a respetiva aplicação é ainda deficiente. A maioria dos sistemas de educação e formação concentram-se ainda largamente na educação e formação dos jovens, e têm sido limitados os progressos na mudança dos sistemas para refletir a necessidade de aprender ao longo da vida. Seria necessário que mais quatro milhões de adultos participassem na aprendizagem ao longo da vida para que se alcançasse 
a taxa de participação do parâmetro de referência acordado pelos Estados-Membros no âmbito do programa "Educação e Formação para 2010". (CCE, 2006).

A necessidade de aumentar a participação dos adultos nas iniciativas do quadro da aprendizagem ao longo da vida continua a ser reforçada como um dos objetivos desta iniciativa. Seguidamente, e ainda no mesmo ano, em 24 de novembro de 2006 é apresentado o Programa de Aprendizagem ao Longo da Vida no Jornal Oficial da União Europeia, que vem reforçar o quadro da aprendizagem ao longo da vida e no âmbito da valorização do Espaço Europeu de Educação, situado à escala planetária, virado para as dimensões económicas através das potencialidades de um crescimento económico e da coesão social da sociedade do conhecimento. O conceito de competência adquire um protagonismo central neste programa, bem como é reforçada a indução de boas práticas e de indicadores de comparação entre os países do Espaço Europeu de Educação.

A ideia da aprendizagem ao longo da vida no seio da União Europeia vem sendo vinculada a uma lógica económica, como esclarece Dale (2008, p. 27), nas "suas versões mais recentes, em especial as promovidas pela $\mathrm{EU}$, têm um tom muito diferente e consistentemente as que apresentem como uma arma crucial de resposta aos desafios gerados pela globalização". É nesta nova versão da aprendizagem que a União Europeia tem investido, desde em 1996, ao designar o Ano Europeu da Aprendizagem ao longo da vida e a partir do qual se intensificou o uso deste conceito em diversos documentos da União Europeia para a Educação, sendo a aprendizagem o princípio orientador do documento Educação e Formação 2010.

Nesse encadeamento, a aprendizagem ao longo da vida é um elemento central do Espaço Europeu de Educação por várias ordens de razões que Dale (2008, p. 28) menciona: a) pela promoção do desenvolvimento de competências; b) pelo enfoque no emprego; c) pela crítica à atual arquitetura dos sistemas educativos e à gramática de escola pelo slogan "aprender em qualquer lugar, a qualquer hora e com quer que seja". Através da aprendizagem ao longo da vida, a Europa cria condições para o desenvolvimento do Espaço Europeu de Educação e para a conquista de uma posição económica e cultural mundial. Todavia, esta convergência em torno desta aprendizagem ao longo da vida pode também conter alguns obstáculos, como nos alerta Griffin (1999), "na Europa, existe agora um consenso sobre os princípios da aprendizagem ao longo da vida e estamos a testemunhar o fim do debate sobre os princípios educativos".

Esse novo quadro de aprendizagem ao longo da vida pode estar imbuído de dois riscos de reducionismo, como alerta Alves (2010, p. 12): o primeiro risco "consiste em subjugar a aprendizagem ao longo da vida a finalidades profissionais e de competitividade económica, reduzindo os processos de aprendizagem dos indivíduos a meios para assegurar a capacidade produtiva de cada um de nós", 
conforme evidenciam diversos documentos emanados pela União Europeia; o segundo atende sobretudo ao facto de a aprendizagem ao longo da vida ser entendida como uma "responsabilidade exclusiva dos indivíduos", negligenciando todos os processos em torno dessa mesma aprendizagem, nomeadamente, a emergência de dinâmicas de aprendizagem e da adesão dos indivíduos às mesmas.

Embora se reconheça uma mudança importante na concetualização da educação, onde a aprendizagem se impõe neste quadro da aprendizagem ao longo da vida, vários autores têm tem uma visão crítica sobre a transição do conceito de educação para o conceito de aprendizagem e competências e para esta centralidade do indivíduo na construção do seu processo educativo, como por exemplo Estêvão (2003), Lima (2010), Griffin (1999), entre outros.

\section{UNIÃO EUROPEIA E PROGRAMA NOVAS OPORTUNIDADES EM PORTUGAL (2005- 2012): PRESSÕES E CONDICIONALISMOS}

O programa Novas Oportunidades, através do processo de RVCC figurou, para muitos portugueses, uma possibilidade de aumentarem as suas qualificações, tanto para nível básico como secundário. A influência da União Europeia na ação concreta dos atores locais, em particular, na gestão dos CNO representou uma das dimensões da investigação encetada. Pretendíamos conhecer as representações dos diretores/coordenadores dos CNO sobre o impacto que os mesmos sentiam em relação às diretrizes emanadas pela União Europeia e que repercussões essas mesmas normas poderiam vir a ter no âmbito dos processos de RVCC.

Numa primeira instância pretendíamos conhecer se os diretores/coordenadores identificavam de facto algum tipo de interferência das políticas educativas da União Europeia, sobretudo através dos programas de financiamento do Fundo Social Europeu (FSE) no desenvolvimento da ação pelos profissionais do CNO. Os dados obtidos no inquérito denunciam que as normas do FSE condicionam a ação do CNO, sendo que 45,5\% dos diretores/coordenadores concordam com esta hipótese e $23,6 \%$ concordam totalmente. Apenas 14,5\% discordam desta afirmação e 16,4\% revelaram não ter opinião formada sobre este impacto, conforme os dados do gráfico 1.

\section{Gráfico 1 - As normas do Fundo Social Europeu condicionam a ação do CNO}

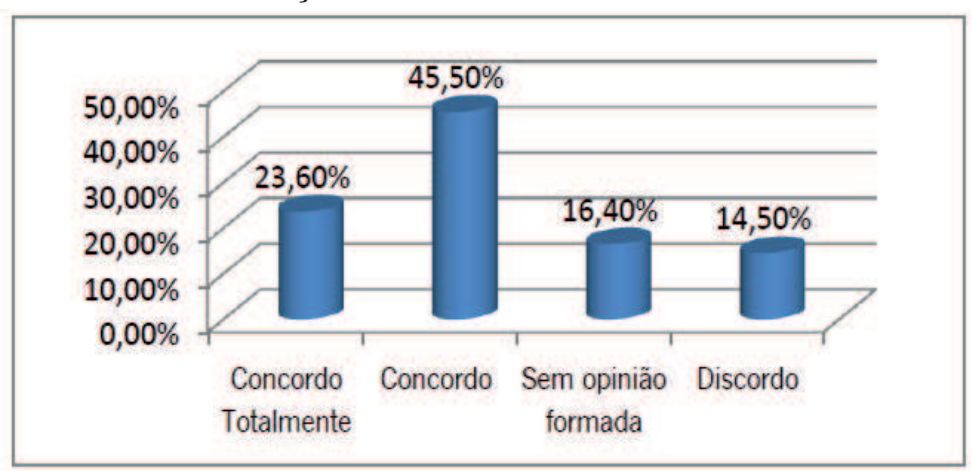


Decorrente dos condicionalismos desvendados nos dados presentes no gráfico 1, consideramos importante conhecer a opinião dos diretores/coordenadores dos CNO sobre o grau de interferência que as políticas educativas/ formação da União Europeia poderiam exercer sobre as políticas educativas nacionais. As convicções dos inquiridos direcionam-se maioritariamente para a concepção de que as políticas da União Europeia influenciam demasiado as políticas educativas nacionais, sendo que 54,5\% concordam e 10,9\% concordam totalmente com esta ideia. Contudo, 20\% dos inquiridos revelou não ter opinião formada sobre este assunto e 14,5\% discordaram deste pendor excessivo das políticas da União Europeia sobre as políticas educativas nacionais.

Gráfico 2 - As políticas de Educação/Formação da União Europeia influenciam demasiado as políticas educativas nacionais

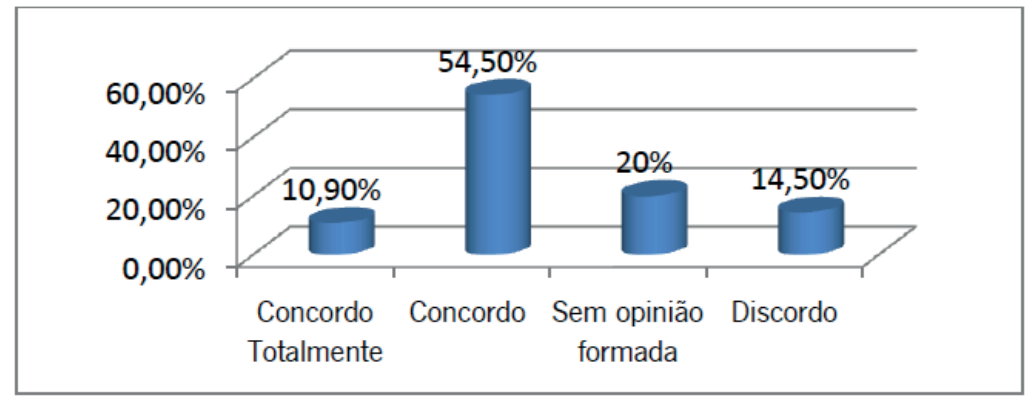

Essa influência deve também ser analisada tendo em consideração outras variáveis, nomeadamente o financiamento, o fornecimento e a regulação do PNO. Tendo como inspiração o trabalho desenvolvido por Dale (2008) e Antunes (2001), podemos, à semelhança do que esta última considera no âmbito das escolas profissionais, analisar as três variáveis no contexto do PNO. No âmbito do financiamento, devemos ter em consideração que este programa se define pelo seu carácter público e estatal, sem qualquer tipo de custos para os adultos. Todavia, no seio do financiamento do PNO, devemos registar o elevado patrocínio por parte dos fundos estruturais da União Europeia e do Estado Português.

Este financiamento é concretizado através de candidaturas a programas específicos da União Europeia, como o POPH e garante a sobrevivência não só da formação nesses contextos organizacionais, como também, em muitos casos, da organização em si. Nesse financiamento, o Estado reformula o seu papel, como explicam Lima, Guimarães e Oliveira (2007, p. 43):

Esta opção surge como resultado de políticas sociais e educativas que sugerem a subtração de certas responsabilidades ao Estado. Deste modo, são multiplicadas as responsabilidades destas organizações, através de transferências de quantias cada vez mais avultadas, acrescentando objetivos e formas de intervir 
4 Sobre os diferentes contextos, Lima e Afonso (2006, p. 211) referem: "Em Portugal, a progressiva erosão do papel do Estado e das políticas públicas no âmbito da educação popular de adultos, que ocorreu de forma mais visível a partir de meados da década de 1980, foi correlativa dos apelos à sociedade civil por parte dos diversos governos, e do protagonismo da lógica da qualificação e da gestão de recursos humanos, com especial incidência no ensino recorrente de adultos e na formação profissional (cf. Lima, 2005)". nas comunidades que nem sempre são articuláveis com as suas finalidades.

Ofornecimento deste programa é proporcionado por várias entidades de natureza diversificada: pública, privada e terceiro sector ${ }^{4}$, sendo que, dentro de cada natureza, vários tipos de organização assumem esta função: escolas públicas, escolas privadas, escolas profissionais, empresas, associações de desenvolvimento local etc. Como explicita a Portaria $\mathrm{n}^{\mathbf{0}} 379$, de 21 de maio de 2008:

Os Centros Novas Oportunidades podem ser criados por entidades públicas ou privadas, adiantedesignadas por entidades promotoras, designadamente estabelecimentos de ensino, centros de formação profissional, autarquias, empresas e associações, com significativa expressão territorial ou sectorial e capacidade técnica instalada, em função sobretudo dos sectores e públicos a que se dirigem.

Portanto, a natureza das organizações é plural, combinando vários tipos de organizações quer escolares quer de natureza empresarial, associativa, entre outras. Esta diversidade de entidades promotoras do RVCC levanos a considerar que, apesar de nos encontrarmos em presença de um programa estatal, no entanto, a execução do mesmo é partilhada por diferentes atores da sociedade civil. Essa situação pode ser interpretada tendo em conta o pensamento de Rodrigues e Stoer (1998, p. 95-96) quando abordam que o contexto português assenta na "tradição de um estado centralizador apesar de (e talvez por isso mesmo) uma fraca provisão social", mas "coexistindo uma 'sociedade providencia' sobretudo baseada em redes de microssolidariedades de natureza mais ou menos informal". Inerente à construção do Estado de bem estar social, até hoje inacabado, a "integração de Portugal em espaço de União Europeia foi fator de reforço, senão mesmo de imposição, de iniciativas de orientação plurissectorial e pluriparceiros" (Rodrigues; Stoer, 1998, p. 96). Nesse contexto, muitas das medidas associadas a programas europeus "pautam-se por critérios de institucionalização de partenariados, tomando, quase sempre, a forma de projectos" (Rodrigues; Stoer, 1998, p. 96).

Contudo, apesar dessa diversidade organizacional, a implementação do PNO, no seio destas organizações, pode estar sujeito aos ditames deste programa, que é alimentado por financiamentos externos às organizações. Nesse âmbito, "a capacidade de intervenção das organizações pode estar comprometida, de resto porque elas assumem funções que resultam frequentemente de processos de privatização de serviços antes assumidos pelo Estado" (Lima; Guimarães; Oliveira, 2007, p. 42).

A regulação do programa Novas Oportunidades é essencialmente estatal, protagonizada pela ANQ, centralizando a definição dos programas, do referencial 
de competências-chave e de todas as orientações técnicopedagógicas e financeiras. O controle é executado não só a partir da execução das metas como também a partir dos programas informáticos (SIGO e SIIFSE). Ao CNO é cometido a gestão pedagógica e financeira, encontrando-se toda a direção situada fora dos CNO. Assim, seguimos a linha de pensamento de Lima, Guimarães e Oliveira (2007, p. 45) quando referem que

[...] uma política pública apenas assente em processos de candidatura e de contratualização parece ignorar as aludidas dificuldades e, sobretudo, centra-se mais na selecção de potenciais parceiros e no controlo das suas acções, do que na promoção das condições educacionais e organizacionais indispensáveis à realização de uma política pública assente na acção de organizações não governamentais prestadoras de serviços.

Embora a execução do PNO esteja a cargo de uma multiplicidade de organizações, a lógica de candidatura aos financiamentos acaba por controlar e transformar a ação dos atores organizacionais, numa reprodução de carácter eminentemente técnico. No quadro 3, clarificamos os seguintes indicadores:

Quadro 3 - Governação do Programa Novas Oportunidades

\begin{tabular}{|c|c|}
\hline Financiamento & Estado/União Europeia \\
\hline Fornecimento & $\begin{array}{c}\text { Plural: Escolas, Associações, Empresas/Setor } \\
\text { Público, Privado, Terceiro Sector }\end{array}$ \\
\hline Regulação & $\begin{array}{c}\text { União Europeia, Estado (ANQ); CNO (apenas } \\
\text { gestão) }\end{array}$ \\
\hline
\end{tabular}

Nesse cenário, podemos concluir que a governação do PNO assenta numa política ambígua e híbrida que coloca o Estado como ator principal no financiamento e na regulação, mas acompanhado por outros protagonistas no fornecimento, cuja natureza é diversificada. Nessa linha de pensamento,

[...] o lançamento do dispositivo de RVCC envolveu um arranjo institucional para a coordenação das atividades (governação) que pode ser sumariamente descrito nos seguintes termos: o financiamento é público, nacional e da UE; o fornecimento e a propriedade são assumidos por entidades públicas, privadas lucrativas, solidarias e comunitárias, de escala nacional e subnacional; a regulação e protagonizada pela UE, o Estado nacional e os fornecedores. A coordenação destas atividades envolve formas institucionais características da burocracia estatal e do (quase) mercado, eventualmente combinadas, em certas circunstancias, com elementos derivados do terceiro sector/comunidade. (Antunes, 2011, p. 21). 
Após a corroboração dos condicionalismos da União Europeia face às políticas educativas nacionais e à ação protagonizada pelos diferentes atores no $\mathrm{CNO}$, era importante analisar se as normas provindas deste contexto internacional tinham em conta as especificidades da política educativa portuguesa, as idiossincrasias dos contextos e dos atores locais. Foi neste intuito que questionamos os diretores/coordenadores dos CNO no sentido de nos indicarem o seu grau de concordância relativamente à eventual harmonia entre as normas da União Europeias e as especificidades do contexto português. Os dados revelam que quase metade dos inquiridos discorda (47,3\%) da ideia de que as normas da União Europeia sejam adequadas à realidade portuguesa. Contudo, deve-se ressalvar que $40 \%$ dos diretores/coordenadores não têm opinião formada sobre este item. Todavia, uma percentagem residual de $12,7 \%$ concordam que as normas da União Europeia são adequadas à realidade portuguesa, conforme se encontra expresso no gráfico 3 .

Gráfico 3 - As normas da União Europeia são adequadas à realidade portuguesa

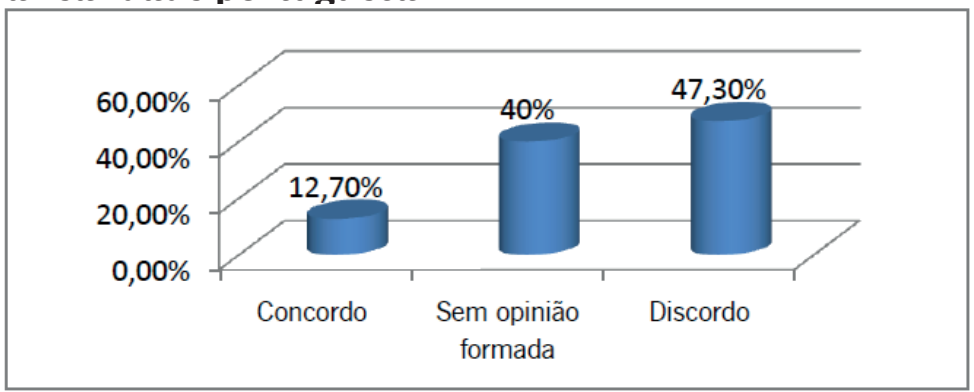

Levando em conta aintegração de Portugal no contexto da União Europeia e o consequente acesso a programas de financiamento da mesma, tornava-se importante perceber até que ponto os atores locais consideravam a relação entre o binómio metas dos CNO e União Europeia como uma conexão importante. Nesse sentido, os diretores/ coordenadores demonstraram maioritariamente que a existência das metas definidas pela $A N Q$ no âmbito do Programa Novas Oportunidades é importante para o cumprimento dos objetivos da União Europeia (52,7\% e $7,3 \%$ concordaram e concordaram totalmente). Cerca de $20 \%$ e $3,6 \%$ dos inquiridos discordaram e discordaram totalmente respetivamente desta concepção, conforme pode ser visualizado no gráfico 4 .

Gráfico 4-As metas definidas pela ANQ são importantes para o cumprimento dos objetivos da União Europeia

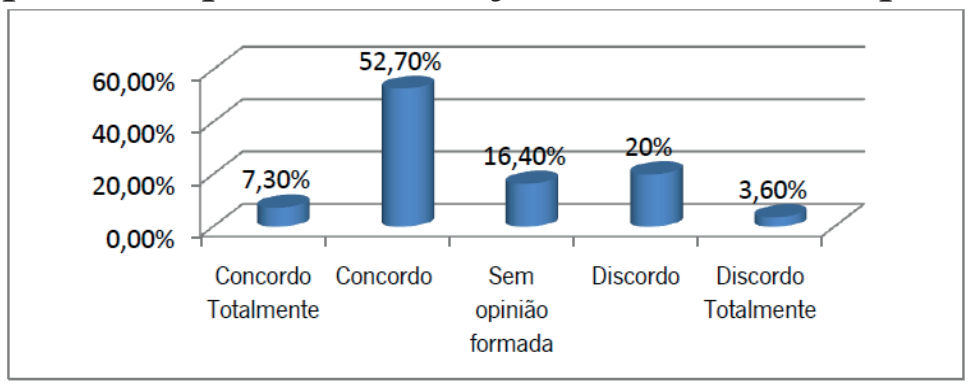


A importância das metas na concretização do PNO é reforçada no âmbito da posição de Portugal no contexto europeu e internacional, dado o caráter eminentemente económico associado à qualificação, como se deduz da afirmação prioritária de objetivos no apoio ao crescimento económico e do emprego do governo de José Sócrates, conforme explicita o discurso do Ministro dos Assuntos Parlamentares, da época, Augusto Santos Silva:

Do ponto de vista do Governo, para garantir a batalha do crescimento da economia e do crescimento do emprego, é preciso agir em cinco frentes: [...] quinta, esforço público e público-privado na promoção da qualificação, seja a qualificação e a aprendizagem dos jovens em idade escolar, seja a da população activa e na dupla vertente da sua certificação escolar e da sua certificação profissional. Ora, esta política económica está em linha com o melhor benchmarking da União Europeia, goza do apoio deste Parlamento e de outras instituições do Estado, das nossas elites económicas, empresariais e sociais e conta com o apoio da generalidade da opinião pública. (Diário da Assembleia da República, Reunião Plenária de 22-6-2006, $\mathrm{n}^{0}$ 138, de 23 de junho de 2006, p. 6316-6317, grifo nosso).

Na linha dos dados obtidos no inquérito aos diretores/ coordenadores, uma das entrevistadas do estudo de caso reconheceu a influência das políticas da União Europeia no âmbito do PNO, nomeadamente a determinação das elevadas metas que os CNO têm de alcançar. Nas suas palavras:

[...] isto surgiu como a ideia de nos colocar ao nível europeu, em qualificações, o mais próximo possível. A nível de escolaridade obrigatória, era uma desgraça. A ideia foi facilitar e ajudar. Concordo porque temos aqui pessoas que, realmente, têm competências ao $9^{\circ}$ ano, mas concordo que este processo deveria ser apenas um processo de reconhecimento de competências, ou seja, as pessoas não deveriam precisar de tanta formação complementar, não deveriam precisar tanto de formação modular para conseguir atingir. Para isso, teriam que ir para os cursos EFA, que também fazem parte das Novas Oportunidades. (Excerto da entrevista $n^{0} 7$ ).

Assim sendo, embora não tenhamos dados que nos permitam aferir o grau de intensidade da porosidade que o PNO revela na absorção dos processos de globalização/ europeização, os dados permitem-nos, contudo, partilhar da opinião de Estêvão (2009, p. 41), quando considera que:

[...] a globalização tem vindo a impor um novo mandato aos diferentes países no sentido de, em nome das vantagens competitivas que podem alcançar, terem de redefinir os seus sistemas de ensino e de formação nacionais em termos de qualidade, avaliada segun- 
do padrões internacionais. Isto exige que os sistemas educacionais se rendam à cultura da performatividade sistémica, através da imposição de indicadores de desempenho como os novos mecanismos de ligação entre o centro que produz a política e as periferias que a põem em prática.

Nessecontexto, reforçamos queaurgência doaumento da elevação das taxas de qualificação dos portugueses, a definição e a construção de um amplo mecanismo de controle, a partir de metas e administração altamente centralizada que o programa Novas Oportunidades, espelham uma clara divisão entre os conceptores de uma política/programa (ANQ) e os executores (CNO). Do mesmo modo, estes condicionantes levantam outras interrogações sobre o processo, nomeadamente, e na linha de pensamento de Barros (2011, p. 162), questiona-se se

[...] as respostas encontradas atualmente nos contextos de práticas de RVCC não dão azo a uma profunda deturpação de uma modalidade educativa realizada com adultos que se deveria caracterizar devido à sua essência crítica da sua própria génese, por um modo de trabalho apropriativo' (cf. Lesne, 1984) assente na real possibilidade de explorar uma relação pedagógica de tipo mais horizontal e, portante, mais problematizador e emancipatório. Ou seja, uma modalidade promissora que afinal as condicionantes impostas centralmente, por Lisboa e por Bruxelas, mais não parecem fazer atualmente do que cooptar, de modo indireto e subtil (numa agenda oculta?), mas de tal modo eficaz e eficiente.

Em suma, podemos considerar o pendor centralizador por parte do Estado sobre as organizações que desenvolvem o PNO, de modo a responder aos desafios supranacionais e ao cumprimento de benchmarks, definidas no âmbito da construção de um projeto europeu do Espaço Europeu de Educação.

\section{CONCLUSÃO}

O aumento da qualificação dos portugueses, através do Programa Novas Oportunidades, coloca Portugal numa posição mais prestigiada no ranking dos países que contribuem para a construção do espaço europeu de educação. O PNO, integrado no âmbito da aprendizagem ao longo da vida, sinaliza as pressões do Estado, da União Europeia e do mercado de aprendizagem. A política de educação/formação da União Europeia, na opinião dos diretores/coordenadores inquiridos, exerce demasiada influência sobre as políticas educativas nacionais, ainda que a maioria dos atores discorde do facto de as mesmas serem adequadas à realidade portuguesa. De igual modo, os atores também consideraram que as normas do Fundo Social Europeu condicionam a ação do CNO e reconhecem que as metas definidas pela ANQ são importantes 
para o cumprimento dos objetivos da União Europeia. Desse modo, sublinha-se a influência dos processos de globalização no contexto local, confirmando a existência de um determinado grau de porosidade, neste programa educativo, das normas e diretrizes da União Europeia. O estudo das dinâmicas de educação de adultos locais de então deve ser entendido num contexto mais amplo da construção do espaço europeu de educação e de globalização.

Podemos assim concluir que a educação de adultos não é um campo monolítico mas antes um campo caraterizado por um compósito de lógicas de ação onde nenhuma lógica assume uma supremacia plena. Assim, a educação de adultos, e em particular o processo de RVCC, é um campo atravessado por diferentes racionalidades, sujeito a um elevado grau de permeabilidade (das influências de organismos internacionais), onde combinam várias lógicas, fruto das pressões exógenas dos contextos internacionais, como das pressões endógenas, inerentes ao Estado português.

\section{REFERÊNCIAS}

AFONSO, Almerindo. "A Redefinição do Papel do Estado e as Políticas Educativas - Elementos para pensar a transição”. Sociologia, Problemas \& Práticas, n. ${ }^{\circ}$ 37, pp. 33-48, 2001.

ALVES, Mariana Gaio. "Aprendizagem ao longo da vida: entre a novidade e a reprodução de velhas desigualdades". Revista Portuguesa de Educação, vol. 23, n. ${ }^{0}$ 1, pp. 7-28, 2010.

ANTUNES, Fátima. "Governação, reforma do Estado e políticas de educação de adultos em Portugal: Pressões globais e especificidades nacionais, tensões e ambivalências". Revista Crítica de Ciências Sociais, 92, pp. 3-29, 2011.

ANTUNES, Fátima. "Os locais das escolas profissionais: Novos papéis para o Estado e a europeização das políticas educativas". In. STOER, Stephen R.; CORTESÃO, Luiza \& CORREIA, José A. (orgs.). Transnacionalização da educação - Da crise da Educação à 'Educação' da Crise. Porto: Edições Afrontamento, 2001, pp. 163-210.

ANTUNES, Fátima. A Nova Ordem Educacional Espaço Europeu de Educação e Aprendizagem ao Longo da Vida. Coimbra: Almedina, 2008.

ANTUNES, Fátima. Políticas Educativas Nacionais e Globalização. Novas Instituições e Processos Educativos. Braga: Universidade do Minho, 2004.

ÁVILA, Patrícia. A Literacia dos Adultos Competências-Chave na Sociedade do Conhecimento. Lisboa: Celta, 2008. 
BARROS, Rosanna. Genealogia dos Conceitos em Educação de Adultos: Da Educação Permanente à Aprendizagem ao Longo da Vida - Um estudo sobre os fundamentos político-pedagógicos da prática educacional. Chiado Editora, 2011.

CAVACO, Cármen. Adultos pouco escolarizados Políticas e Práticas de Formação. Lisboa: Educa, 2009..

COMISSÃO DAS COMUNIDADES EUROPEIAS (2000). Memorando sobre a aprendizagem ao Longo da Vida. Documento de Trabalho dos Serviços da Comissão. Bruxelas, 30.10.2000 SEC (2000) 1832, In http://www.alv. gov.pt/info2.asp, [consultado em 2007/01/10)].

COMISSÃO DAS COMUNIDADES EUROPEIAS (2001). Tornar o espaço europeu de aprendizagem ao longo da vida uma realidade. Comunicação da Comissão de 21/11/2001 (COM(2001) 678 final). Bruxelas. In http:// ec.europa.eu/education/policies/1l1/life/communication/ com_pt., [consultado em 2007/01/10].

COMISSÃO DAS COMUNIDADES EUROPEIAS (2006). Educação de Adultos: nunca é tarde para aprender. Comunicação da Comissão. Bruxelas. In. Eurlex.europa.Eu/LexUriServ/LexUriServ. do?uri=COM:2006:0614:FIN:PT,pdf [consultado em 2007/01/10]

DALE, Roger. "Globalização e educação: demonstrando a existência de uma 'cultura educacional mundial comum' ou localizando uma 'agenda globalmente estruturada para a educação'?”. Educação, Sociedade, \& Cultura, n. ${ }^{0}$ 16, pp. 133-169, 2001,

DALE, Roger. "Construir a Europa através de um Espaço Europeu de Educação”. Revista Lusófona de Educação, n. ${ }^{\circ} 11$, pp. 13-30. 2008,

DIÁRIO DA ASSEMBLEIA DA REPÚBLICA. Reunião Plenária de 22-6-2006, n. ${ }^{\circ}$ 138, de 23-6-2006

ESTÊVÃO,Carlos. "Educação, globalizaçõesecosmopolitismos: novos direitos, novas desigualdades”. Revista Portuguesa de Educação, 22(2), pp. 35-52, 2009.

ESTÊVÃO, Carlos. "Ideologia e Gestão das Competências". Teoria e Prática da Educação. Maringá: Universidade Estadual de Maringá. v. 6, nº13, pp. 209-357, 2003.

GRIFFIN, Colin. "Lifelong learning and social democracy". International Journal of Lifelong Education, v. 18, n. 5, pp. 329-342, 1999.

GUIMARÃES, Paula. Políticas de educação de adultos em Portugal (1999-2006) - A emergência da educação para a competitividade. (Tese de Doutoramento), Braga: Universidade do Minho /Instituto de Educação 2010. 
LIMA, Licínio \& AFONSO, Almerindo (2006). "Políticas públicas, novos contextos e actores em educação de adultos". In LIMA, Licínio C. (Org.). Educação Não Escolar de Adultos. Iniciativas em Contextos Associativos. Braga: Universidade do Minho/Unidade de Educação de Adultos, 2006, pp. 205-229.

LIMA, Licínio. “A Educação de Adultos em Portugal (19742004). Entre as lógicas de Educação Popular e da gestão de recursos humanos". In. CANÁRIO, R. \& CABRITO, B. Educação e Formação de Adultos, Mutações e Convergências. Lisboa: Educa, 2005, pp. 31-60.

LIMA, Licínio. "A Educação faz tudo? Critica ao pedagogismo na 'sociedade da aprendizagem"”. Revista Lusófona de Educação, n. ${ }^{0}$ 15, pp. 41-54, 2010.

LIMA, Licínio; GUIMARÃES, Paula; \& OLIVEIRA, Raquel. "Organização Associativa e Produção Local de Políticas de Educação de Adultos". In. CASTRO, Rui Vieira (org.); LIMA, Licínio C.; DIONÍSIO, Maria Lourdes; GUIMARÃES, Paula; OLIVEIRA, Raquel \& SANCHO, Amélia Vitória. Contexto Organizacional, Orientações e Práticas de Educação de Adultos - Os Cursos EFA numa Associação Local. Vila Verde: ATAHCA/UEA-UM, 2007, pp. 15-44.

PORTUGAL - Decreto-Lei n.o ${ }^{\circ}$ 208/2002, de 17 de outubro.

PORTUGAL - Decreto-Lei n. ${ }^{\circ}$ 36/2012, de 15 de fevereiro.

PORTUGAL - Decreto-Lei n.o ${ }^{\circ}$ 387/99, de 28 de setembro.

PORTUGAL - Portaria n. ${ }^{\circ}$ 379/20o8, de 21 de maio.

RODRIGUES, Fernanda \& STOER, Stephen. Entre Parceria e Partenariado. Oeiras: Celta, 1998.

SANTOS, Boaventura Sousa (2001). "Os processos da globalização”. In___ (org), Globalização-Fatalidade ou Utopia? Porto: Edições Afrontamento. pp. 31-110.

TEODORO, António. "Organizações internacionais e políticas educativas nacionais: A emergência de novas formas de regulação transnacional, ou de uma globalização de baixa intensidade”. In: STOER, Stephen. R., CORTESÃ̃, Luiza \& CORREIA, José A. (orgs). Transnacionalização da educação: Da Crise da Educação à "educação" da crise. Porto: Afrontamento, 2001. pp. 126-158. 